\title{
Assessing Global Ocean Wind Energy Resources Using Multiple Satellite Data
}

\author{
Qiaoying Guo ${ }^{1,2,3}$, Xiazhen $\mathrm{Xu}^{4}$, Kangyu Zhang ${ }^{1,2,3}$ (D), Zhengquan Li ${ }^{5}$, Weijiao Huang ${ }^{6}$, \\ Lamin R. Mansaray ${ }^{1,2,7}$ (D), Weiwei Liu ${ }^{1,2}$, Xiuzhen Wang ${ }^{8}$, Jian Gao ${ }^{8}$ and Jingfeng Huang ${ }^{1,2,3, *}$ \\ 1 Institute of Applied Remote Sensing and Information Technology, Zhejiang University, \\ Hangzhou 310058, China; qiaoyingguo@zju.edu.cn (Q.G.); kangyuzhang@zju.edu.cn (K.Z.); \\ lmansaray@zju.edu.cn (L.R.M.); weiweiliu@zju.edu.cn (W.L.) \\ 2 Key Laboratory of Agricultural Remote Sensing and Information Systems, Hangzhou 310058, China \\ 3 State Key Laboratory of Satellite Ocean Environment Dynamics, Second Institute of Oceanography, \\ State Oceanic Administration, Hangzhou 310012, China \\ 4 Jiangsu Climate Centre, Jiangsu Meteorological Bureau, Nanjing 210009, China; Xuxz0119@126.com \\ 5 Zhejiang Climate Centre, Zhejiang Meteorological Bureau, Hangzhou 310007, China; lzq110119@163.com \\ 6 Department of Land Management, Zhejiang University, Hangzhou 310058, China; huangweijiao@zju.edu.cn \\ 7 Department of Agro-meteorology and Geo-informatics, Magbosi Land, Water and Environment Research \\ Centre (MLWERC), Sierra Leone Agricultural Research Institute (SLARI), Freetown PMB 1313, Sierra Leone \\ 8 Institute of Remote Sensing and Earth Sciences, Hangzhou Normal University, Hangzhou 311121, China; \\ wxz05160516@126.com (X.W.); gaojiannj@126.com (J.G.) \\ * Correspondence: hjf@zju.edu.cn; Tel.: +86-571-8898-2830
}

Received: 29 October 2017; Accepted: 9 January 2018; Published: 12 January 2018

\begin{abstract}
Wind energy, as a vital renewable energy source, also plays a significant role in reducing carbon emissions and mitigating climate change. It is therefore of utmost necessity to evaluate ocean wind energy resources for electricity generation and environmental management. Ocean wind distribution around the globe can be obtained from satellite observations to compensate for limited in situ measurements. However, previous studies have largely ignored uncertainties in ocean wind energy resources assessment with multiple satellite data. It is against this background that the current study compares mean wind speeds (MWS) and wind power densities (WPD) retrieved from scatterometers (QuikSCAT, ASCAT) and radiometers (WindSAT) and their different combinations with National Data Buoy Center (NDBC) buoy measurements at heights of $10 \mathrm{~m}$ and $100 \mathrm{~m}$ (wind turbine hub height) above sea level. Our results show an improvement in the accuracy of wind resources estimation with the use of multiple satellite observations. This has implications for the acquisition of reliable data on ocean wind energy in support of management policies.
\end{abstract}

Keywords: wind energy resources; QuikSCAT; WindSAT; ASCAT; global ocean

\section{Introduction}

Climate change is a global issue that impacts on all human beings: an associated rising of sea level, extreme hydrologic events (such as floods and droughts) and urban heat island effects are projected to occur with climate change. Such changes have already affected human health due to extreme heat, cold, drought, storms and crop failures [1]. Scientists have demonstrated that global warming over millennial time scales is due to greenhouse gas emissions produced by human activities [2,3]. Energy use efficiency and renewable energy generation can benefit public health and the global climate system by displacing emissions from fossil-fuelled electricity generation units [4]. Expanding renewable energy, especially wind power, is a central strategy for reducing carbon emissions and mitigating climate change $[5,6]$. Therefore, the evaluation of wind resources plays a significant role in the selection 
of appropriate sites for the establishment of wind farms, wind energy development, and national energy policy formulation. In most countries, coastal areas have become heavily urbanized and industrialized as a consequence of agglomeration. In effect, more energy will be required in these areas. As environmental sustainability continues to occupy the center stage of the global development agenda, offshore wind has been regarded as a potential renewable energy source that can be generated through a network of wind turbines. Currently, more than $91 \%$ of all the offshore wind installations worldwide are in European waters, particularly in the North Sea [7].

Although offshore wind energy has huge potential in powering the global economy, there are spatial and temporal variabilities in the distribution of wind power, dynamics which are worth investigating for the development of efficient and sustainable offshore wind energy resources. Offshore wind energy resources are mainly estimated from in situ wind measurements [8], satellite data, numerical simulation results [9], and reanalysis data [10-12]. With progress in microwave remote sensing, a great deal of satellite-derived data have been obtained and applied in the study of wind energy resources, including sea surface wind distribution data derived from Synthetic Aperture Radars (SAR) and scatterometers, such as the Earth Resources Satellite ERS-2 SAR (1995-2011) [13,14], Environment Satellite (ENVISAT) Advanced Synthetic Aperture Radar (ASAR) (2002-2012) [14-19], RADARSAT-1 SAR (1995-2013) [20], SeaWinds onboard QuikSCAT (1999-2009) [17,19-27], ASCAT onboard METOP-A (2007-present) [17,18,27,28] and OceanSat-2 scatterometer (OSCAT, 2009-present) [28,29]. Wind fields retrieved from SAR imagery have a high spatial resolution $(<100 \mathrm{~m})$. However, from previous research, there are less than 1500 overlapping SAR samples $[14,15,17]$, and SAR cannot obtain observations of the whole ocean. Scatterometers and passive microwave radiometers can provide global sea surface wind fields at a relatively coarse resolution of approximately $12.5-50 \mathrm{~km}$ with two observations per day from single satellite data.

A number of studies have been conducted on ocean wind energy assessment at a variety of spatial scales (from local through regional to global). Early studies evaluated offshore or global ocean wind power resources mainly derived from single satellite data. It should be emphasized however that, generally, only a maximum of two observations per day (at descending and ascending passes) are obtainable from a single satellite. As diurnal ocean wind variations are apparent, statistics derived from a single satellite are limited both synoptically and spatially and therefore using multiple sources of satellite data are imperative to gain a more comprehensive recording and analysis of ocean wind energy in space and time [14,17]. A growing number of studies are now focusing on wind resources assessment based on multiple satellite data $[17-20,27,28]$, albeit with the reduction of uncertainties largely ignored.

The purpose of the current study is to estimate the uncertainty associated with the number of satellite observations and its impact on the accuracy of ocean wind resources assessment derived from multiple satellite data. The spatial variability of global ocean wind energy resources is assessed at heights of $10 \mathrm{~m}$ and $100 \mathrm{~m}$ to provide relevant data on the selection of wind energy sites.

\section{Data}

\subsection{QuikSCAT, WindSAT and ASCAT Data}

In this study, two types of time series satellite data-which can provide sea surface wind fields at a spatial resolution of $0.25^{\circ} \times 0.25^{\circ}$ and at a height of $10 \mathrm{~m}$ above sea level-have been utilized, including scatterometer (QuikSCAT and ASCAT) and radiometer (WindSAT) wind data. The scatterometer operates by transmitting microwave pulses to the ocean surface and then measuring the microwave pulses returned to the satellite sensor. This backscattered signal is physically related to surface roughness. For water surfaces, the surface roughness is highly correlated with the near-surface wind speed and direction at a height of $10 \mathrm{~m}$ above sea level. The GMF is the Geophysical Model Function which relates the observed backscatter ratio to surface wind speed and direction at a height of $10 \mathrm{~m}$ 
above sea level. However, the passive microwave radiometer wind vector data are retrieved from the microwave brightness temperatures measurements using Radiative Transfer Model (RTM).

SeaWinds scatterometer is the main instrument on the QuikSCAT satellite and operates at Ku band (13.4 GHz) which is sensitive to rain. Ku-2011 GMF was used. However, the advanced scatterometer (ASCAT) onboard Metop-A satellite is working at C band $(5.3 \mathrm{GHz})$, and C band GMF (C-2015) had been used. The impact of rain on wind retrieval is less severe for ASCAT C-band data than for QuikSCAT Ku-band data. The wind products contain rain flags and researchers can remove rain effects from the datasets by discarding these data. This has been done in the current analysis. The WindSAT fully polarimetric radiometer, as a passive microwave sensor, operates in five discrete channels: 6.8, $10.7,18.7,23.8$, and $37.0 \mathrm{GHz}$. All are fully polarimetric except the 6.8 and $23.8 \mathrm{GHz}$ channels that have only dual polarization.

Wind products used herein are the daily gridded maps from Remote Sensing Systems [30]. Table 1 summarizes the information from multiple satellite data including the maximum numbers of different satellite data in the two over pass times and per month. There are two observations based on a single satellite sensor per day. The total number of satellite data is about $9000-12,000$ from $20^{\circ} \mathrm{S}$ to $18^{\circ} \mathrm{N}$, and is about $12,000-14,000$ among all satellite data at $20-35^{\circ} \mathrm{S}$ and $18-35^{\circ} \mathrm{N}$. The total number of satellite data is about $14,000-16,000$ at $35-45^{\circ} \mathrm{S}$ and $35-42^{\circ} \mathrm{N}$, and is about $16,000-21,609$ among all satellite data at $45-60^{\circ} \mathrm{S}$ and $42-80^{\circ} \mathrm{N}$. However there are $2000-10,000$ at latitude $60-90^{\circ} \mathrm{S}$ and some areas of the North Pole (the north of Asia and North America). Furthermore, rain flags may be more prevalent in the equatorial East Pacific and the eastern part of the Indian Ocean because these regions have fewer numbers than adjacent areas (9000-10,000).

Table 1. Total numbers of QuikSCAT, WindSAT and ASCAT wind data in descending/ascending (des./asc.) mode and per month in local solar time.

\begin{tabular}{|c|c|c|c|}
\hline Satellite Platform & QuikSCAT & Coriolis & MetOp-A \\
\hline Instrument & SeaWinds & WindSAT & ASCAT \\
\hline Band of operation & $\mathrm{Ku}(13.4 \mathrm{GHz})$ & $\begin{array}{c}5 \text { discrete channels: } 6.8, \\
10.7,18.7,23.8 \text {, and } 37.0 \\
\text { GHz }\end{array}$ & $\mathrm{C}(5.3 \mathrm{GHz})$ \\
\hline Total & 6944 & 8372 & 6379 \\
\hline Ascending & 3514 & 4197 & 3194 \\
\hline Descending & 3430 & 4175 & 3185 \\
\hline January & 549 & 665 & 486 \\
\hline February & 512 & 609 & 445 \\
\hline March & 567 & 701 & 549 \\
\hline April & 560 & 683 & 521 \\
\hline May & 562 & 690 & 555 \\
\hline June & 580 & 618 & 537 \\
\hline July & 610 & 696 & 554 \\
\hline August & 656 & 736 & 557 \\
\hline September & 620 & 739 & 532 \\
\hline October & 612 & 751 & 552 \\
\hline November & 539 & 735 & 535 \\
\hline December & 577 & 749 & 556 \\
\hline Time period & 1999-2009 & 2003-current & 2007-current \\
\hline Time of datasets & 1999.07-2009.11 & $2003.02-2015.12$ & 2007.03-2015.12 \\
\hline Descending node time & 06:00 & 06:00 & $9: 30$ \\
\hline Ascending node time & $18: 00$ & $18: 00$ & $21: 30$ \\
\hline Spatial resolution & $0.25^{\circ} \times 0.25^{\circ}$ & $0.25^{\circ} \times 0.25^{\circ}$ & $0.25^{\circ} \times 0.25^{\circ}$ \\
\hline Produce version & $\mathrm{V} 4$ & V7.0.1 & V2.1 \\
\hline
\end{tabular}




\subsection{NDBC Buoys Data}

The National Data Buoy Center (NDBC) [31] provides average hourly wind vector measurements recorded at 39 buoys around North America (shown in Figure 1). These NDBC buoys are commonly operated and maintained by American government organizations to report on winds, waves and other ocean conditions at strategic locations for the purposes of ocean navigation, search and rescue operations, and scientific research. The 39 buoy measurements were selected as validation data and they provide a longer time series of meteorological observations relative to QuikSCAT, WindSAT and ASCAT data from 1999 to 2015. These NDBC buoys provided hourly wind vector measurements at a height of 4 or $5 \mathrm{~m}$ above sea level. The wind profile method (in Section 3.1) has been used in this study to extrapolate wind speed to heights of $10 \mathrm{~m}$ and $100 \mathrm{~m}$ above sea level in order to compare with satellite data at the same height. The distances from buoys to coastline are greater than $30 \mathrm{~km}$, and the water depths of the buoys' positions range from $16 \mathrm{~m}$ to $5230 \mathrm{~m}$. There are 32 buoys at water depths greater than $50 \mathrm{~m}$ so a large amount of the buoys may not be influenced by coastal effects.

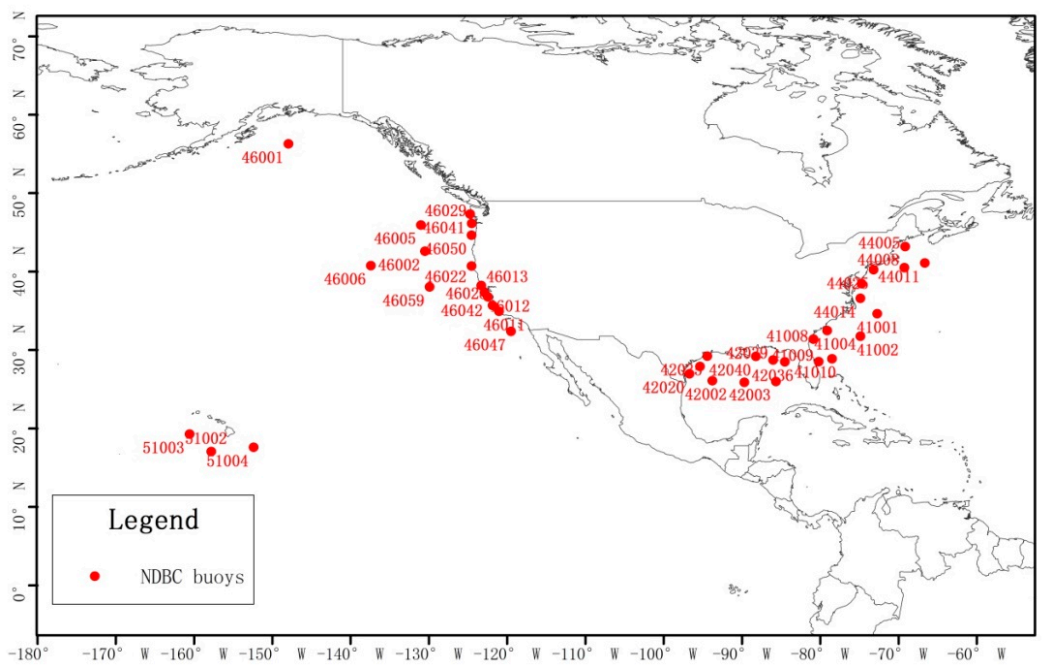

Figure 1. Location of National Data Buoy Center (NDBC) buoys providing hourly wind vector measurements used for comparison with satellite data.

\section{Methodology}

\subsection{Wind Profile Method}

In order to compare the wind energy resources derived from buoys with those from satellite data at the same height, the extrapolated wind speed $V$ at heights of $10 \mathrm{~m}$ or $100 \mathrm{~m}(z)$ is calculated from Equation(1) [32]:

$$
V(z)=\frac{u_{*}}{\kappa}\left[\ln \left(\frac{z}{z_{0}}\right)-\psi_{m}\right]
$$

where $V$ is the wind speed at height $z . \kappa$ is the von Karman constant $(\sim 0.4)$. The parameter $\psi_{m}$ is a correction for atmospheric stability effects (here $\psi_{m}$ is set to zero to estimate neutral winds, following Badger et al. [32]). In this paper, the effect of atmospheric stability is ignored due to the lack of relevant data. The long-term stability correction $\left(\psi_{m}\right)$ is usually positive under stable conditions and negative under unstable conditions, and this may lead to an underestimation of mean wind speeds when assuming neutral atmospheric conditions. Knowing the spatial distribution of $\psi_{m}$ is beneficial to improving the accuracy of wind speed extrapolation. The parameter $\psi_{m}$ ranges from -2.5 to 0 at a height of $100 \mathrm{~m}$ in the south Baltic Sea based on SAR and WRF model data, and there is a wind speed difference of $0.5 \mathrm{~m} / \mathrm{s}$ with and without the long-term atmospheric stability correction at a height of $100 \mathrm{~m}$ based on meteorological mast observations (Fino-2) [32]. Takeyama et al. [33] pointed out that 
atmospheric stability can cause an error of about -1 to $+1 \mathrm{~m} / \mathrm{s}$ without stability correction at a height of $10 \mathrm{~m}$ based on SAR images over the Japanese coastal waters. The sea surface roughness length $z_{0}$ can be estimated from Equation (2):

$$
z_{0}=\alpha_{c} \frac{u_{*}^{2}}{g}
$$

where $\alpha_{c}$ is the Charnock's parameter (here set to 0.0144, following Badger et al. [32]), and $g$ is the gravitational acceleration of the Earth. The sea surface friction velocity $u_{*}$ can be estimated by combining and solving iteratively from Equations (1) and (2) when the wind speed at a single level is known.

\subsection{Wind Resource Assessment Method}

The mean wind speed (MWS) is the wind speed averaged over a given time period and is given as:

$$
\bar{V}=\frac{1}{N} \sum_{i=1}^{N} V_{i}
$$

where $\bar{V}$ is the mean wind speed $(\mathrm{m} / \mathrm{s}), V_{i}$ is the wind speed $(\mathrm{m} / \mathrm{s})$ at measurement $i$ at a given height, $N$ is the total number of measurements.

The wind power density (WPD) may be estimated by statistical method (Equation (4)) [34,35] and the Weibull probability distribution function of two parameters (Equation (5)) $[17,19,21,27,32,34,35]$.

$$
\begin{gathered}
\mathrm{E}_{\text {statistic }}=\frac{1}{2} \rho \overline{V_{i}^{3}} \\
\mathrm{E}_{\text {weibull }}=\frac{1}{2} \rho C^{3} \Gamma\left(1+\frac{3}{k}\right)
\end{gathered}
$$

where $\mathrm{E}$ is the wind power density $\left(\mathrm{W} / \mathrm{m}^{2}\right)$, and $\rho$ is the standard sea-level air density $\left(1.225 \mathrm{~kg} / \mathrm{m}^{3}\right)[11,12,19,27,28]$. $C$ is the scale parameter $(\mathrm{m} / \mathrm{s})$, and $k$ is the dimensionless shape parameter. Several methods have been applied to calculate Weibull parameters $C$ and $k$, such as the method using mean and standard deviation of wind speed samples. In this study, we have used the formulae $[21,27,34,35]$ given as follows:

$$
\begin{aligned}
& k=(\sigma / \bar{V})^{-1.086} \\
& C=\bar{V} / \Gamma\left(1+\frac{1}{k}\right)
\end{aligned}
$$

where $\sigma$ is the standard deviation of wind speed. $\Gamma$ is the gamma function.

In this study, we assume the probability density function of the wind speeds to follow the Weibull distribution, and based on a comparison of the WPD derived by the statistical method and that by the Weibull distribution function from 39 buoys (in Section 2.2), the RMSE is $4.8 \mathrm{~W} / \mathrm{m}^{2}$ at a height of $10 \mathrm{~m}$ and $9.9 \mathrm{~W} / \mathrm{m}^{2}$ at a height of $100 \mathrm{~m}$.

\section{Results}

\subsection{Evaluation of MWS and WPD Derived from Multiple Satellite Data Compared with Buoy Measurement Data}

The mean wind speeds (MWS) and wind power densities (WPD) calculated from 39 NDBC buoys during 1999-2015 have been compared with those derived from QuikSCAT, WindSAT and ASCAT, and their different combinations at heights of $10 \mathrm{~m}$ and $100 \mathrm{~m}$ above sea level as presented in Tables 2-5. In this section, the RMSE, Bias, correlation coefficient (Corr.), $\mathrm{R}^{2}$ and Slope are used to compare satellite-derived MWS/WPD with 39 buoy-derived MWS/WPD at heights of $10 \mathrm{~m}$ and 
$100 \mathrm{~m}$. Tables 2-5 reveal that MWS/WPD derived from ASCAT have better accuracies than those from WindSAT and QuikSCAT in terms of RMSE. QuikSCAT and ASCAT overestimated the MWS and WPD derived from buoys (positive biases and slopes greater than 1.00), while WindSAT shows a tendency to underestimate the MWS and WPD in terms of negative biases and slopes. From the Remote Sensing Systems, QuikSCAT shows similar wind speeds to those from ASCAT, and wind speeds from QuikSCAT/ASCAT are slightly higher than those from WindSAT (the differences between wind speeds are within $0.1 \mathrm{~m} / \mathrm{s}$ ), wind speeds from QuikSCAT have lower errors than those from WindSAT in terms of bias compared with aircraft measurements. This may be due to the different sensor configurations and wind retrieval algorithms.

QuikSCAT + WindSAT-derived MWS/WPD at heights of $10 \mathrm{~m}$ and $100 \mathrm{~m}$ show lower errors in terms of RMSE and higher correlations than QuikSCAT-derived MWS/WPD and WindSAT-derived MWS/WPD. WindSAT + ASCAT-derived MWS at heights of $10 \mathrm{~m}$ and $100 \mathrm{~m}$ show lower errors (lower RMSE, biases and slopes are equal to 0.00 and 1.00 respectively) and higher correlations than WindSAT-derived MWS and ASCAT-derived MWS. WindSAT + ASCAT-derived WPD at heights of $10 \mathrm{~m}$ and $100 \mathrm{~m}$ show lower errors in terms of RMSE and higher correlations than WindSAT-derived WPD and ASCAT-derived WPD. QuikSCAT + WindSAT + ASCAT-derived WPD at heights of $10 \mathrm{~m}$ and $100 \mathrm{~m}$ show the lowest errors in terms of RMSE and highest correlations. The result of this comparison shows that a better accuracy of MWS/WPD may be derived from multiple satellite data than from single satellite data.

Table 2. Statistics of the comparison between buoy-derived mean wind speeds (MWS) and satellite-derived MWS (m/s) at a height of $10 \mathrm{~m}$ above sea level.

\begin{tabular}{ccccccc}
\hline Different Combinations of Satellite Data & RMSE & Bias & Corr. & $\mathbf{R}^{2}$ & Slope & N \\
\hline QuikSCAT & 0.39 & 0.23 & 0.91 & 0.78 & 1.03 & $4134-7063$ \\
WindSAT & 0.36 & -0.07 & 0.90 & 0.81 & 0.99 & $3474-7643$ \\
ASCAT & 0.33 & 0.09 & 0.90 & 0.77 & 1.01 & $2717-4017$ \\
QuikSCAT + WindSAT & 0.27 & 0.10 & 0.94 & 0.87 & 1.01 & $8307-14,586$ \\
QuikSCAT + ASCAT & 0.35 & 0.18 & 0.91 & 0.78 & 1.02 & $7209-11,080$ \\
WindSAT + ASCAT & 0.28 & 0.00 & 0.93 & 0.86 & 1.00 & $6272-11,086$ \\
QuikSCAT + WindSAT + ASCAT & 0.27 & 0.10 & 0.94 & 0.86 & 1.01 & $11,229-18,029$ \\
\hline
\end{tabular}

Here, the intercept of linear regression is set to zero, and the number of satellite observations at different buoy positions is indicated by $\mathrm{N}$ (min-max).

Table 3. Statistics of the comparison between buoy-derived wind power densities (WPD) and satellite-derived WPD $\left(\mathrm{W} / \mathrm{m}^{2}\right)$ at a height of $10 \mathrm{~m}$ above sea level.

\begin{tabular}{ccccccc}
\hline Different Combinations of Satellite Data & RMSE & Bias & Corr. & $\mathbf{R}^{\mathbf{2}}$ & Slope & N \\
\hline QuikSCAT & 55.4 & 34.6 & 0.91 & 0.82 & 1.09 & $4134-7063$ \\
WindSAT & 53.5 & -19.7 & 0.88 & 0.78 & 0.95 & $3474-7643$ \\
ASCAT & 42.2 & 4.7 & 0.91 & 0.81 & 1.01 & $2717-4017$ \\
QuikSCAT + WindSAT & 37.0 & 9.9 & 0.93 & 0.87 & 1.02 & $8307-14,586$ \\
QuikSCAT + ASCAT & 47.5 & 23.3 & 0.91 & 0.83 & 1.06 & $7209-11,080$ \\
WindSAT + ASCAT & 40.5 & -9.2 & 0.92 & 0.84 & 0.97 & $6272-11,086$ \\
QuikSCAT + WindSAT + ASCAT & 36.9 & 8.7 & 0.93 & 0.87 & 1.02 & $11,229-18,029$ \\
\hline
\end{tabular}

Table 4. Statistics of the comparison between buoy-derived MWS and satellite-derived MWS (m/s) at a height of $100 \mathrm{~m}$ above sea level.

\begin{tabular}{ccccccc}
\hline Different Combinations of Satellite Data & RMSE & Bias & Corr. & $\mathbf{R}^{\mathbf{2}}$ & Slope & N \\
\hline QuikSCAT & 0.48 & 0.29 & 0.91 & 0.78 & 1.03 & $4134-7063$ \\
WindSAT & 0.45 & -0.09 & 0.90 & 0.81 & 0.99 & $3474-7643$ \\
ASCAT & 0.40 & 0.11 & 0.90 & 0.77 & 1.01 & $2717-4017$ \\
QuikSCAT + WindSAT & 0.33 & 0.12 & 0.94 & 0.87 & 1.01 & $8307-14,586$ \\
QuikSCAT + ASCAT & 0.43 & 0.22 & 0.91 & 0.79 & 1.03 & $7209-11,080$ \\
WindSAT + ASCAT & 0.34 & 0.00 & 0.93 & 0.86 & 1.00 & $6272-11,086$ \\
QuikSCAT + WindSAT + ASCAT & 0.34 & 0.12 & 0.94 & 0.86 & 1.01 & $11,229-18,029$ \\
\hline
\end{tabular}


Table 5. Statistics of the comparison between buoy-derived WPD and satellite-derived WPD $\left(\mathrm{W} / \mathrm{m}^{2}\right)$ at a height of $100 \mathrm{~m}$ above sea level.

\begin{tabular}{ccccccc}
\hline Different Combinations of Satellite Data & RMSE & Bias & Corr. & $\mathbf{R}^{\mathbf{2}}$ & Slope & N \\
\hline QuikSCAT & 105.0 & 65.6 & 0.91 & 0.82 & 1.09 & $4134-7063$ \\
WindSAT & 101.1 & -37.0 & 0.88 & 0.77 & 0.95 & $3474-7643$ \\
ASCAT & 79.2 & 8.3 & 0.91 & 0.81 & 1.01 & $2717-4017$ \\
QuikSCAT + WindSAT & 70.2 & 18.8 & 0.93 & 0.87 & 1.03 & $8307-14,586$ \\
QuikSCAT + ASCAT & 89.6 & 44.0 & 0.91 & 0.83 & 1.06 & $7209-11,080$ \\
WindSAT + ASCAT & 76.8 & -17.5 & 0.92 & 0.84 & 0.97 & $6272-11,086$ \\
QuikSCAT + WindSAT + ASCAT & 69.8 & 16.4 & 0.93 & 0.87 & 1.02 & $11,229-18,029$ \\
\hline
\end{tabular}

In order to verify the impact of data sampling density (random sampling numbers of satellite observations) on the accuracy of satellite-derived MWS and WPD at $10 \mathrm{~m}$ and $100 \mathrm{~m}$ above sea level, we acquired 100 MWS/WPD random samples $(500,1000,1500, \ldots, 11,000)$ from all satellite observations (QuikSCAT + WindSAT + ASCAT) by sampling 100 times repeatedly. The 100 satellite-derived MWS/WPD samples were compared with the buoy-derived MWS/WPD at each buoy position (39 NDBC buoy in total) and at different sampling densities using RMSE. Figures 2 and 3 illustrate the variation of mean RMSE as a function of sampling density at $10 \mathrm{~m}$ and $100 \mathrm{~m}$ above sea level. The result shows that more satellite observations may reduce the uncertainty in MWS and WPD estimation at $10 \mathrm{~m}$ and $100 \mathrm{~m}$ above sea level. This result is consistent with the research results of Barthelmie, Pryor and Hasager [17,36].
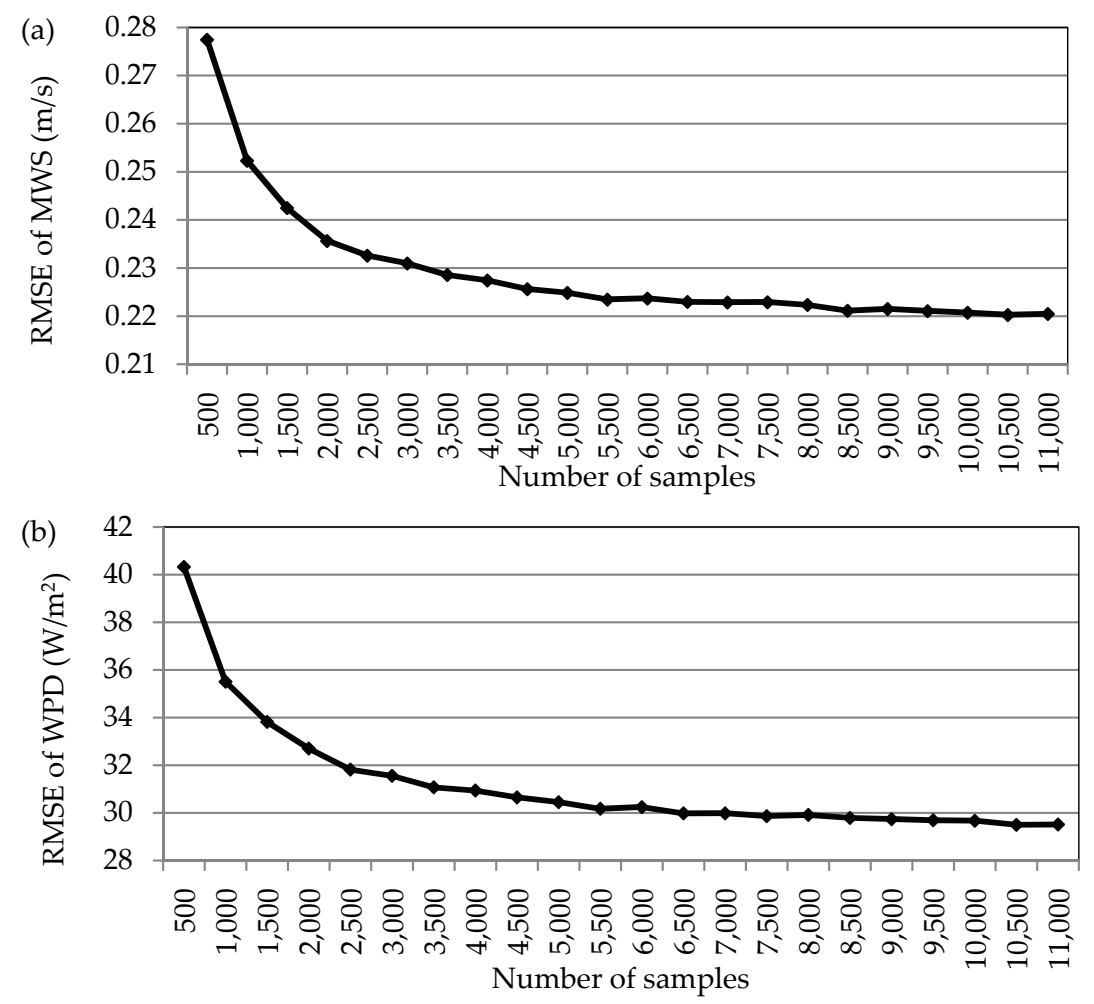

Figure 2. The mean RMSE of MWS and WPD from random sampling of all satellite observations (QuikSCAT + WindSAT + ASCAT) with different numbers of samples compared to the buoy-derived MWS and WPD at a height of $10 \mathrm{~m}$ above sea level. (a) MWS, and (b) WPD. 

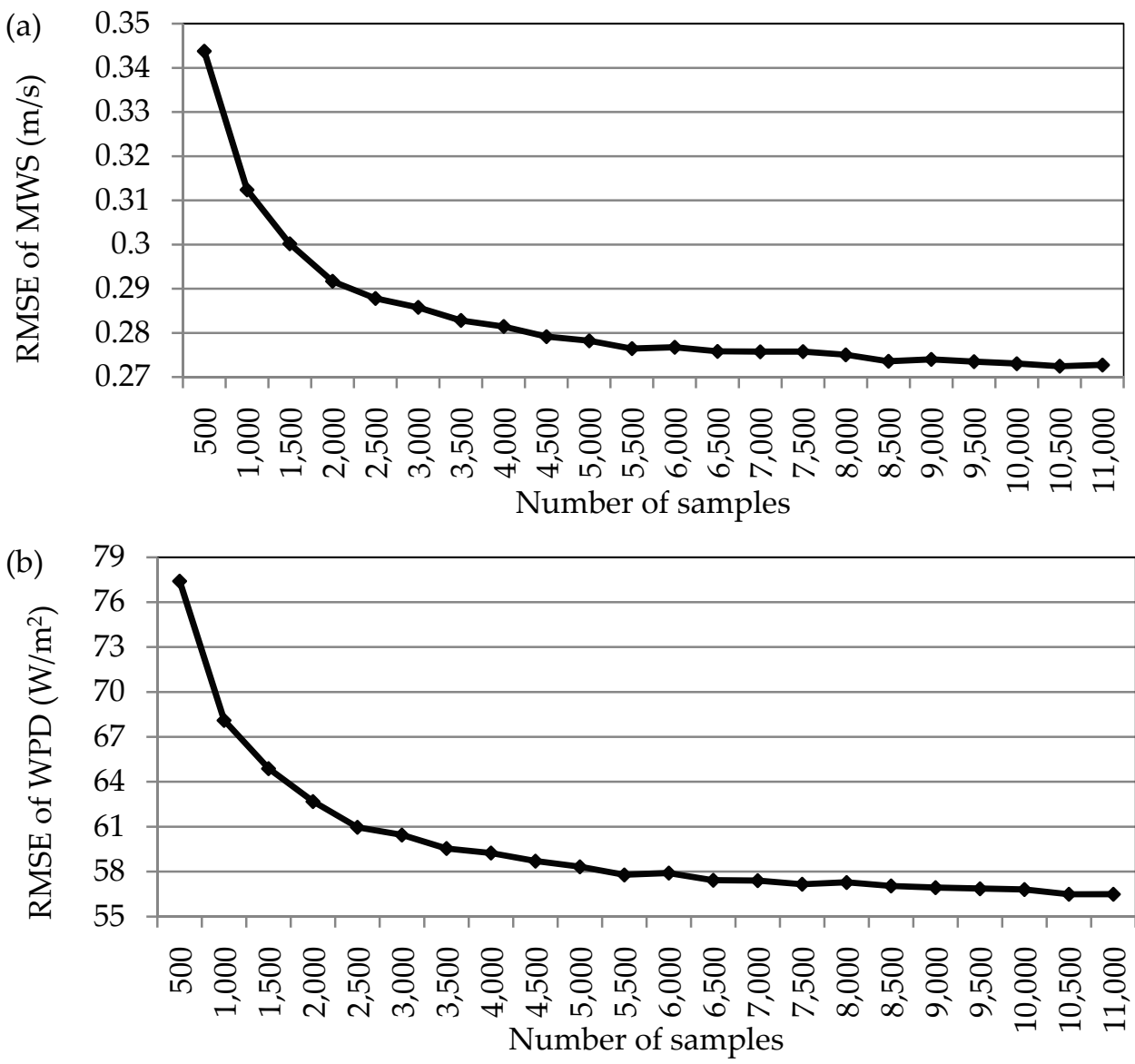

Figure 3. The mean RMSE of MWS and WPD from random sampling of all satellite observations (QuikSCAT + WindSAT + ASCAT) with different numbers of samples compared to the buoy-derived MWS and WPD at a height of $100 \mathrm{~m}$ above sea level. (a) MWS, and (b) WPD.

\subsection{Spatial Variability of Global Ocean Wind Energy Resources Using Multiple Satellite Data}

The geographic distribution of global MWS and WPD at $10 \mathrm{~m}$ above sea level using multiple satellite data (QuikSCAT + WindSAT + ASCAT) is shown in Figure 4. It can be observed that the distribution of wind energy exhibits significant regional differences across the global ocean. The MWS at most global ocean regions are higher than $3 \mathrm{~m} / \mathrm{s}$, with the areas of highest MWS being primarily distributed around the Southern Hemisphere westerlies $(8-13 \mathrm{~m} / \mathrm{s})$. The Northern Hemisphere westerlies are also areas of relatively high MWS (8-11 m/s), whereas MWS in the low latitudes are in the range of $3-10 \mathrm{~m} / \mathrm{s}$. The MWS at the Northern European Seas is $6.5-10 \mathrm{~m} / \mathrm{s}$, a result similar to that of Hasager et al. [17] who used ASAR, ASCAT and QuikSCAT and Badger et al. [37] based on ASAR. High wind areas in the middle of the Indian Ocean $(7-10 \mathrm{~m} / \mathrm{s})$ and the East China Sea $(7-10 \mathrm{~m} / \mathrm{s})$ may mainly be influenced by the winter monsoon, and the strong wind in the Arabian Sea $(6-9 \mathrm{~m} / \mathrm{s})$ and the South China Sea $(6.5-9 \mathrm{~m} / \mathrm{s})$ may mainly be caused by the summer monsoon as discussed by Liu et al. [21] based on QuikSCAT. The highest wind speeds in China are found in the southeastern region, especially along the coastline of Fujian Province and the Strait of Taiwan. This finding is also consistent with Jiang et al. [26] who used QuikSCAT. The MWS of Southeastern Brazil at a height of $10 \mathrm{~m}$ above sea level is 6-9 m/s which is similar to the result of Pimenta et al. [22] based on QuikSCAT. The global oceanic MWS values at a height of $10 \mathrm{~m}$ above sea level reported by our study are slightly higher than those by Atlas et al. [38], which were based on SSM/I (Special Sensor Microwave Imager) data acquired from 1987 to 1994. 
The WPD at most global ocean regions are higher than $200 \mathrm{~W} / \mathrm{m}^{2}$. The areas of higher WPD at $10 \mathrm{~m}$ above sea level are mainly distributed around the Southern $\left(400-1600 \mathrm{~W} / \mathrm{m}^{2}\right)$ and Northern (400-1300 W/ $\mathrm{m}^{2}$ ) Hemisphere westerlies. This observed phenomenon may be influenced by the westerly winds. However, WPD in the low latitudes are about 50-600 W/ $\mathrm{m}^{2}$. The coast of Somalia and Southeast China show relatively higher WPD $\left(>400 \mathrm{~W} / \mathrm{m}^{2}\right)$ which is largely attributable to tropical monsoon weather conditions typical in these areas. On the other hand, WPD in the equatorial regions are generally less than $200 \mathrm{~W} / \mathrm{m}^{2}$. Equatorial regions are generally characterized by low atmospheric pressure conditions with a muted seasonal cycle. The high WPD at the North Atlantic Ocean may be due to the ocean-atmosphere interaction around the warm current of the Mexico Gulf and the cold eddy of the Labrador Sea in winter [21]. The distribution of global oceanic WPD at $10 \mathrm{~m}$ above sea level presented in this paper is largely consistent with the results of Zheng and Pan [11].

The geographic distribution of global MWS and WPD at $100 \mathrm{~m}$ above sea level using multiple satellite data (QuikSCAT + WindSAT + ASCAT) is shown in Figure 5. The MWS at most global ocean regions are higher than $4 \mathrm{~m} / \mathrm{s}$, with the areas of highest MWS being primarily distributed around the Southern Hemisphere westerlies (9-16 m/s). The areas of Northern Hemisphere westerlies also have relatively high MWS (9-14 m/s), whereas MWS in the low latitudes are in the range of 4-12 m/s. The MWS at the North Sea and South China Sea are 8-12 m/s and 6.5-10 m/s respectively, a result similar to that of Hasager et al. [39] who used SSM/I data from 1988 to 2013 at a height of $100 \mathrm{~m}$ above sea level.

The areas of higher WPD at $100 \mathrm{~m}$ above sea level are mainly distributed around the Southern (800-3200 W/ $\left.\mathrm{m}^{2}\right)$ and Northern (800-2800 W/m² $)$ Hemisphere westerlies. This observed phenomenon may be influenced by the westerly winds. However, WPD in the low latitudes are about 150-1200 W/ $\mathrm{m}^{2}$.
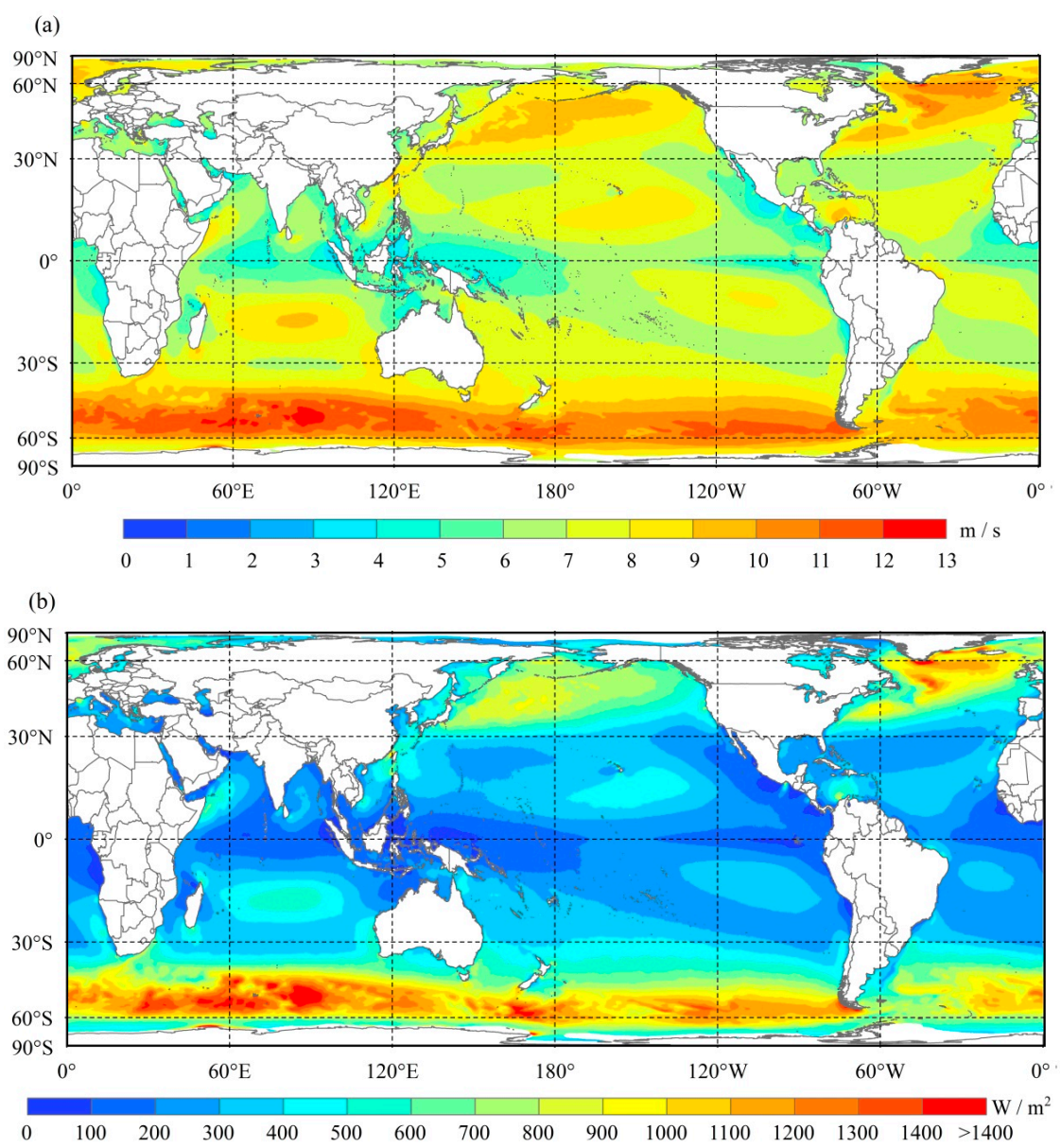

Figure 4. The distribution of global MWS and WPD at $10 \mathrm{~m}$ above sea level derived from QuikSCAT+ WindSAT + ASCAT during the period 1999-2015. (a) MWS, and (b) WPD. 
(a)

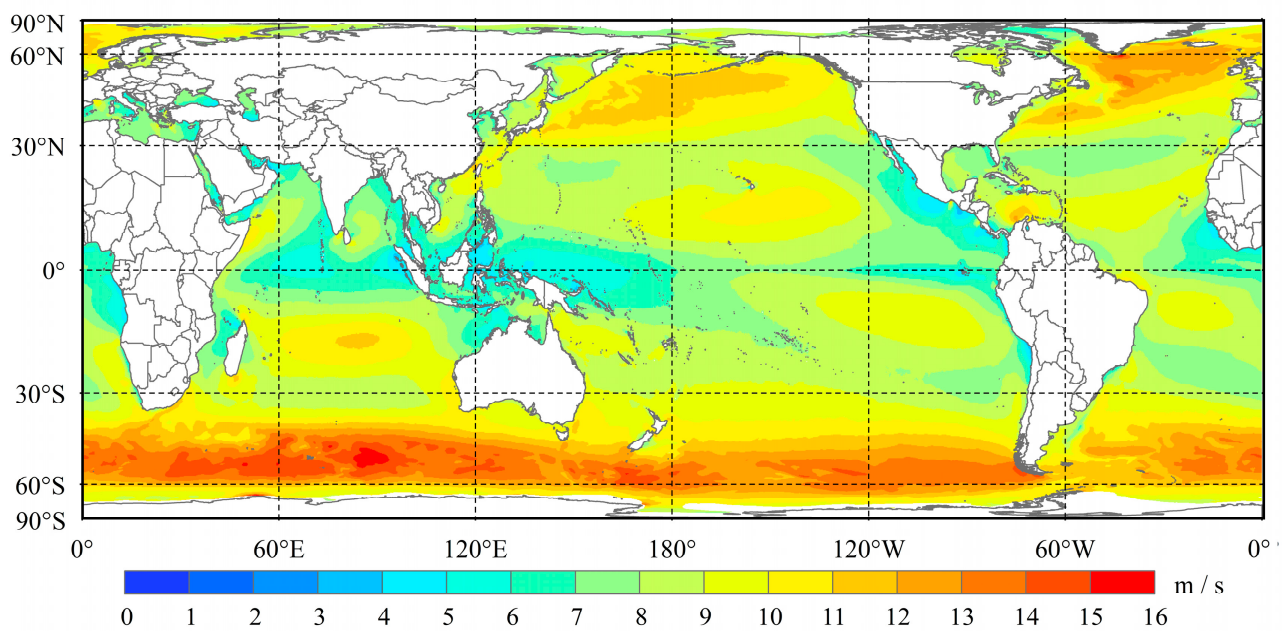

(b)

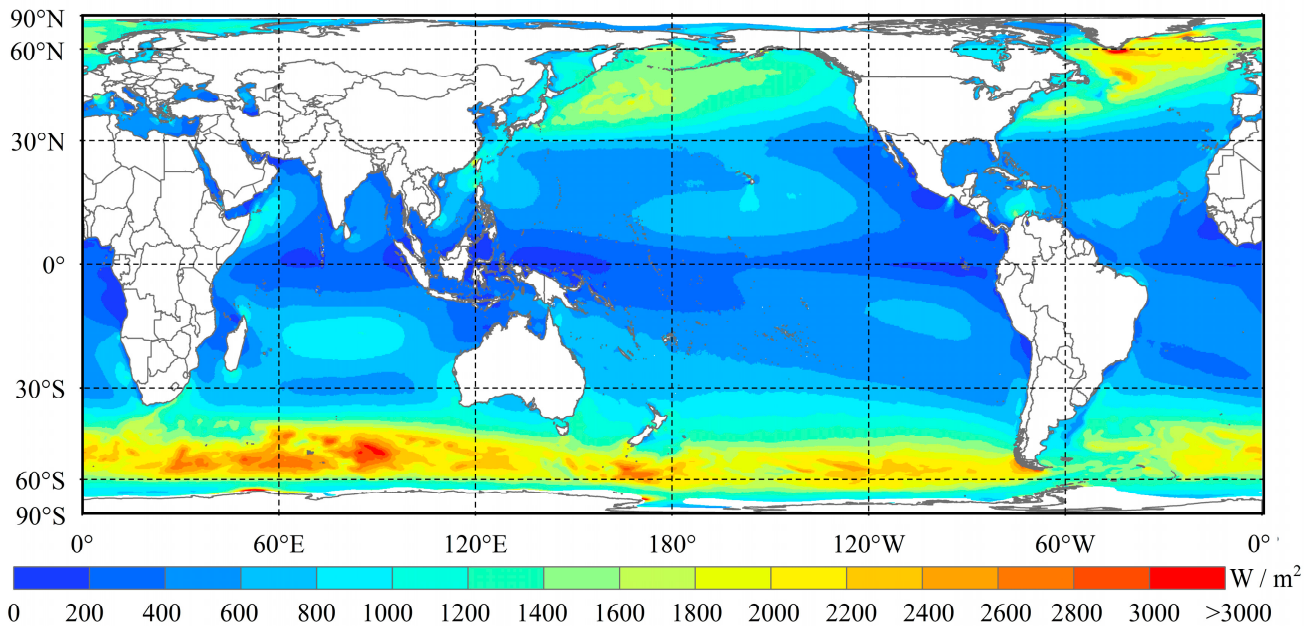

Figure 5. The distribution of global MWS and WPD at $100 \mathrm{~m}$ above sea level derived from QuikSCAT + WindSAT + ASCAT during the period 1999-2015. (a) MWS, and (b) WPD.

\section{Discussion}

Despite the results provided by this study, we do acknowledge that the uncertainties in ocean wind resources estimation can also be generated from other factors, such as the accuracy of wind vector retrieval algorithms, sensor configurations and the impact of diurnal variability on satellite wind observations. Removal of hard targets at sea (including ships, wind turbines, oil platforms etc.) is also significant for increasing the accuracy of wind retrieval from satellite images [17].

In this study, the number of satellite observations is still limited based on QuikSCAT, WindSAT and ASCAT. In future operational scenarios, there could be more satellite datasets with much improved resolution and thus a higher precision of wind vector retrievals. Based on our results, we hereby recommend the use of more satellite observations (including those from OSCAT, RapidSCAT etc.) which may be evaluated by further analysis.

The distribution of global ocean wind resources at heights of $10 \mathrm{~m}$ and $100 \mathrm{~m}$ (wind turbine hub height) above sea level has been mapped in this study. However, wind farm wake effects were ignored. A quantification and prediction of the wake effect losses is challenging because of the complex aerodynamic nature of the interdependencies of turbines [40] and therefore deserves greater attention in future studies. Atmospheric stability also plays a significant role in the accuracy of wind speed extrapolation. Therefore, in future research or operational scenarios, the use of information on 
atmospheric stability is highly recommended to ensure more accurate wind resources assessment at regional and global scales.

\section{Conclusions}

To develop an understanding of the spatial variability of global ocean wind resources using multiple satellite data, the spatial distribution of mean wind speeds (MWS) and wind power densities (WPD) at $10 \mathrm{~m}$ and $100 \mathrm{~m}$ above sea level have been mapped in this study using QuikSCAT + WindSAT + ASCAT data.

In this study, MWS and WPD calculated from 39 NDBC buoys during 1999-2015 are first compared with those derived from QuikSCAT, WindSAT and ASCAT, and their different combinations at heights of $10 \mathrm{~m}$ and $100 \mathrm{~m}$ (wind turbine hub height) above sea level. The results show that for single satellite data, MWS and WPD derived from ASCAT have the lowest RMSE. QuikSCAT and ASCAT overestimated the MWS and WPD derived from buoys, while WindSAT shows a tendency to underestimate MWS and WPD given their respective biases and slopes. This phenomenon may be due to the different sensor configurations and wind retrieval algorithms. Meanwhile, QuikSCAT + WindSAT + ASCAT-derived WPD at heights of $10 \mathrm{~m}$ and $100 \mathrm{~m}$ show the lowest RMSE and highest correlations, and hence a better accuracy of MWS/WPD may be derived from multiple satellite data than from single satellite data.

Furthermore, we quantified the impacts of data sampling density (number of satellite observations) on the accuracy of satellite-derived MWS and WPD at $10 \mathrm{~m}$ and $100 \mathrm{~m}$ above sea level. The results show an increase in the accuracy of MWS/WPD estimation with satellite observations, at $10 \mathrm{~m}$ and $100 \mathrm{~m}$ above sea level.

Acknowledgments: This work was supported by the China Special Fund for Industrial and Scientific Research in the Public Interest (Meteorology), under Grant GYHY201306050. The authors would like to thank the Remote Sensing Systems for providing QuikSCAT, WindSAT and ASCAT data, and the National Data Buoy Center for the provision of NDBC buoy data.

Author Contributions: Jingfeng Huang conceived the original idea of the study, and designed, organized and supervised the entire investigation; Qiaoying Guo collected, processed and analyzed the data, and wrote the article; Xiuzhen Wang and Jian Gao assisted in data collection and preprocessing; Xiazhen Xu, Kangyu Zhang, Zhengquan Li, Weijiao Huang and Weiwei Liu assisted in data processing and analysis; Lamin R. Mansaray assisted in manuscript preparation and revision.

Conflicts of Interest: The authors declare no conflict of interest.

\section{References}

1. Patz, J.A.; Campbell-Lendrum, D.; Holloway, T.; Foley, J.A. Impact of regional climate change on human health. Nature 2005, 438, 310-317. [CrossRef] [PubMed]

2. Snyder, C.W. Evolution of global temperature over the past two million years. Nature 2016, 538, $226-228$. [CrossRef] [PubMed]

3. Stern, P.C.; Sovacool, B.K.; Dietz, T. Towards a science of climate and energy choices. Nat. Clim. Chang. 2016, 6, 547-555. [CrossRef]

4. Buonocore, J.J.; Luckow, P.; Norris, G.; Spengler, J.D.; Biewald, B.; Fisher, J.; Levy, J.I. Health and climate benefits of different energy-efficiency and renewable energy choices. Nat. Clim. Chang. 2015, 6, 100-105. [CrossRef]

5. Barthelmie, R.J.; Pryor, S.C. Potential contribution of wind energy to climate change mitigation. Nat. Clim. Chang. 2014, 4, 684-688. [CrossRef]

6. Lu, X.; McElroy, M.B.; Peng, W.; Liu, S.; Nielsen, C.P.; Wang, H. Challenges faced by China compared with the US in developing wind power. Nat. Energy 2016, 1. [CrossRef]

7. Zheng, C.W.; Li, C.Y.; Pan, J.; Liu, M.Y.; Xia, L.L. An overview of global ocean wind energy resource evaluations. Renew. Sustain. Energy Rev. 2016, 53, 1240-1251. [CrossRef]

8. Kucukali, S.; Dinçkal, Ç. Wind energy resource assessment of Izmit in the West Black Sea Coastal Region of Turkey. Renew. Sustain. Energy Rev. 2014, 30, 790-795. [CrossRef] 
9. Mattar, C.; Borvarán, D. Offshore wind power simulation by using WRF in the central coast of Chile. Renew. Energy 2016, 94, 22-31. [CrossRef]

10. Chadee, X.T.; Clarke, R.M. Large-scale wind energy potential of the Caribbean region using near-surface reanalysis data. Renew. Sustain. Energy Rev. 2014, 30, 45-58. [CrossRef]

11. Zheng, C.W.; Pan, J. Assessment of the global ocean wind energy resource. Renew. Sustain. Energy Rev. 2014, 33, 382-391. [CrossRef]

12. Zheng, C.W.; Pan, J.; Li, C.Y. Global oceanic wind speed trends. Ocean Coast. Manag. 2016, 129, 15-24. [CrossRef]

13. Hasager, C.B.; Nielsen, M.; Astrup, P.; Barthelmie, R.; Dellwik, E.; Jensen, N.O.; Jørgensen, B.H.; Pryor, S.C.; Rathmann, O.; Furevik, B.R. Offshore wind resource estimation from satellite SAR wind field maps. Wind Energy 2005, 8, 403-419. [CrossRef]

14. Christiansen, M.B.; Koch, W.; Horstmann, J.; Bayhasager, C.; Nielsen, M. Wind resource assessment from C-band SAR. Remote Sens. Environ. 2006, 105, 68-81. [CrossRef]

15. Hasager, C.B.; Badger, M.; Peña, A.; Larsén, X.G.; Bingöl, F. SAR-Based Wind Resource Statistics in the Baltic Sea. Remote Sens. 2011, 3, 117-144. [CrossRef]

16. Chang, R.; Zhu, R.; Badger, M.; Hasager, C.; Zhou, R.; Ye, D.; Zhang, X. Applicability of Synthetic Aperture Radar Wind Retrievals on Offshore Wind Resources Assessment in Hangzhou Bay, China. Energies 2014, 7, 3339-3354. [CrossRef]

17. Hasager, C.B.; Mouche, A.; Badger, M.; Bingöl, F.; Karagali, I.; Driesenaar, T.; Stoffelen, A.; Peña, A.; Longépé, N. Offshore wind climatology based on synergetic use of Envisat ASAR, ASCAT and QuikSCAT. Remote Sens. Environ. 2015, 156, 247-263. [CrossRef]

18. Chang, R.; Zhu, R.; Badger, M.; Hasager, C.; Xing, X.; Jiang, Y. Offshore Wind Resources Assessment from Multiple Satellite Data and WRF Modeling over South China Sea. Remote Sens. 2015, 7, 467-487. [CrossRef]

19. Doubrawa, P.; Barthelmie, R.J.; Pryor, S.C.; Hasager, C.B.; Badger, M.; Karagali, I. Satellite winds as a tool for offshore wind resource assessment: The Great Lakes Wind Atlas. Remote Sens. Environ. 2015, 168, 349-359. [CrossRef]

20. Beaucage, P.; Lafrance, G.; Lafrance, J.; Choisnard, J.; Bernier, M. Synthetic aperture radar satellite data for offshore wind assessment: A strategic sampling approach. J. Wind Eng. Ind. Aerodyn. 2011, 99, 27-36. [CrossRef]

21. Liu, W.T.; Tang, W.; Xie, X. Wind power distribution over the ocean. Geophys. Res. Lett. 2008, 35. [CrossRef]

22. Pimenta, F.; Kempton, W.; Garvine, R. Combining meteorological stations and satellite data to evaluate the offshore wind power resource of Southeastern Brazil. Renew. Energy 2008, 33, 2375-2387. [CrossRef]

23. Capps, S.B.; Zender, C.S. Global ocean wind power sensitivity to surface layer stability. Geophys. Res. Lett. 2009, 36. [CrossRef]

24. Capps, S.B.; Zender, C.S. Estimated global ocean wind power potential from QuikSCAT observations, accounting for turbine characteristics and siting. J. Geophys. Res. 2010, 115. [CrossRef]

25. Karamanis, D.; Tsabaris, C.; Stamoulis, K.; Georgopoulos, D. Wind energy resources in the Ionian Sea. Renew. Energy 2011, 36, 815-822. [CrossRef]

26. Jiang, D.; Zhuang, D.; Huang, Y.; Wang, J.; Fu, J. Evaluating the spatio-temporal variation of China's offshore wind resources based on remotely sensed wind field data. Renew. Sustain. Energy Rev. 2013, 24, 142-148. [CrossRef]

27. Bentamy, A.; Croize-Fillon, D. Spatial and temporal characteristics of wind and wind power off the coasts of Brittany. Renew. Energy 2014, 66, 670-679. [CrossRef]

28. Carvalho, D.; Rocha, A.; Gómez-Gesteira, M.; Silva Santos, C. Offshore winds and wind energy production estimates derived from ASCAT, OSCAT, numerical weather prediction models and buoys-A comparative study for the Iberian Peninsula Atlantic coast. Renew. Energy 2017, 102, 433-444. [CrossRef]

29. Gadad, S.; Deka, P.C. Offshore wind power resource assessment using Oceansat-2 scatterometer data at a regional scale. Appl. Energy 2016, 176, 157-170. [CrossRef]

30. Remote Sensing Systems. Available online: http://www.remss.com/missions (accessed on 12 April 2016).

31. National Data Buoy Center. Available online: http:/ / www.ndbc.noaa.gov (accessed on 1 September 2016).

32. Badger, M.; Peña, A.; Hahmann, A.N.; Mouche, A.A.; Hasager, C.B. Extrapolating satellite winds to turbine operating heights. J. Appl. Meteorol. Climatol. 2016, 55, 975-991. [CrossRef] 
33. Takeyama, Y.; Ohsawa, T.; Kozai, K.; Hasager, C.B.; Badger, M. Comparison of geophysical model functions for SAR wind speed retrieval in Japanese coastal waters. Remote Sens. 2013, 5, 1956-1973. [CrossRef]

34. Mohammadi, K.; Shamshirband, S.; Yee, P.L.; Petkovic, D.; Zamani, M.; Ch, S. Predicting the wind power density based upon extreme learning machine. Energy 2015, 86, 232-239. [CrossRef]

35. Mohammadi, K.; Alavi, O.; Mostafaeipour, A.; Goudarzi, N.; Jalilvand, M. Assessing different parameters estimation methods of Weibull distribution to compute wind power density. Energy Convers. Manag. 2016, 108, 322-335. [CrossRef]

36. Barthelmie, R.J.; Pryor, S.C. Can satellite sampling of offshore wind speeds realistically represent wind speed distributions? J. Appl. Meteorol. 2003, 42, 83-94. [CrossRef]

37. Badger, M.; Badger, J.; Nielsen, M.; Hasager, C.B.; Pena, A. Wind class sampling of satellite SAR imagery for offshore wind resource mapping. J. Appl. Meteorol. Climatol. 2010, 490, 2474-2491. [CrossRef]

38. Atlas, R.; Hoffman, R.N.; Bloom, S.C.; Jusem, J.C.; Ardizzone, J. A multiyear global surface wind velocity dataset using SSM/I wind observations. Bull. Am. Meteorol. Soc. 1996, 77, 869-882. [CrossRef]

39. Hasager, C.B.; Astrup, P.; Zhu, R.; Chang, R.; Badger, M.; Hahmann, A.N. Quarter-century offshore winds from SSM/I and WRF in the North Sea and South China Sea. Remote Sens. 2016, 8, 769. [CrossRef]

40. Ritter, M.; Pieralli, S.; Odening, M. Neighborhood effects in wind farm performance: A regression approach. Energies 2017, 10, 365. [CrossRef]

(C) 2018 by the authors. Licensee MDPI, Basel, Switzerland. This article is an open access article distributed under the terms and conditions of the Creative Commons Attribution (CC BY) license (http://creativecommons.org/licenses/by/4.0/). 